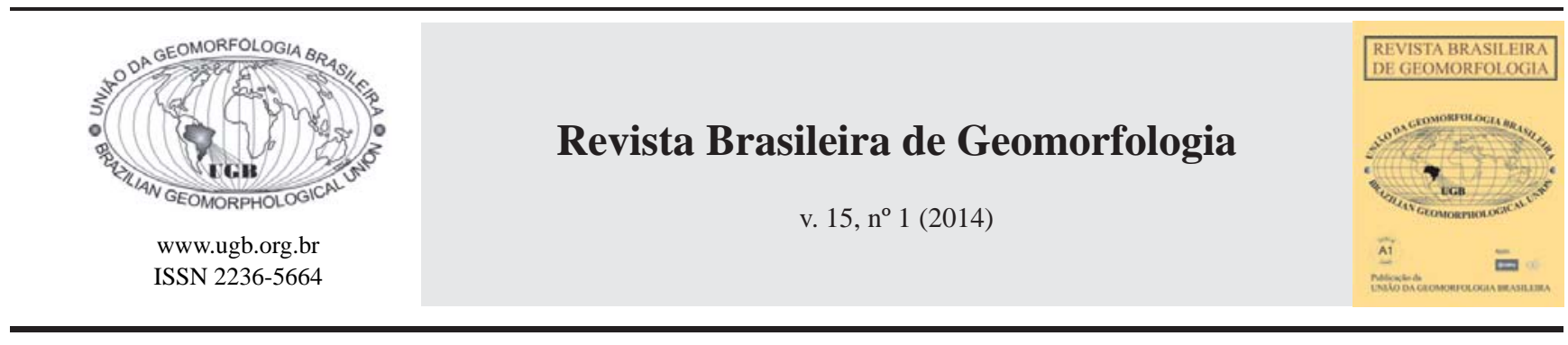

\title{
IDENTIFICAÇÃO E MAPEAMENTO DOS PROCESSOS EROSIVOS NA BACIA HIDROGRÁFICA DO RIO CAETÉ, NO MUNICÍPIO DE ALFREDO WAGNER/SC
}

\section{IDENTIFICATION AND MAPPING OF EROSION PROCESSES IN CAETÉ RIVER CATCHMENT, MUNICIPALITY OF ALFREDO WAGNER, BRAZIL}

\author{
Leandro Redin Vestena \\ Departamento de Geografia, Universidade Estadual do Centro-Oeste. \\ Rua Simão Varela de Sá, nº 03 - Vila Carli CEP 85040-080 - Guarapuava/PR, Brasil. \\ E-mail: lvestena@unicentro.br
}

Masato Kobiyama

Instituto de Pesquisas Hidráulicas, Universidade Federal do Rio Grande do Sul . Av. Bento Gonçalves, 9500, Caixa Postal 15029 CEP 91507-970 - Porto Alegre/RS, Brasil.

E-mail: masato.kobiyama@ufrgs.br

\section{Informações sobre o Artigo}

Data de Recebimento:

16/02/2012

Data de Aprovação:

29/10/2013

\section{Palavras-chave:}

Processos erosivos; limitantes

de erosão; modelagem

hidrogeomorfológica.

\section{Keywords:}

Erosion processes;

erosion threshold;

hydrogeomorphological

modelling.

\section{Resumo}

O presente estudo teve por objetivo identificar e mapear os processos erosivos na bacia hidrográfica do Rio Caeté, município de Alfredo Wagner/SC. O modelo proposto por Dietrich et al. (1992), foi utilizado para determinar espacialmente os diferentes processos erosivos, a partir da combinação de características locais como declividade, área de contribuição da encosta de montante e propriedades do solo. Os resultados demonstram a presença de áreas com elevado grau de instabilidade das encostas, suscetíveis a deslizamentos. A bacia do Caeté apresenta características naturais que potencializam a ocorrência dos processos erosivos. $\mathrm{O}$ zoneamento dos processos erosivos potenciais predominantes na bacia do Rio Caeté fornece subsídios a ações de caráter preventivo e mitigador.

\begin{abstract}
Current analysis identifies and maps the erosion processes in the Caeté river catchment in the municipality of Alfredo Wagner SC Brazil. Model by Dietrich et al. (1992) was employed to determine spatially the different erosion processes by local characteristics such as slopes, upstream hillside area and soil properties. Results show the presence of areas with high instability on hillsides susceptible to landslides. The Caeté river catchment has natural characteristics that may cause the occurrence of erosion processes. The zoning of predominant potential erosion processes in the Caeté river catchment is a great support to prevent and mitigate their effects.
\end{abstract}




\section{Introdução}

A intervenção humana, na bacia hidrográfica do Rio Caeté (BRC), no município de Alfredo Wagner/SC, por meio da agricultura em áreas com elevada declividade e o desmatamento de margens de rios, propicia a redução da infiltração de água no solo e, por conseguinte, o aumento do fluxo superficial, desencadeando fluxo torrencial sob fortes chuvas (CHECCHIA et al., 2004; VESTENA et al., 2011).

Os impactos negativos dos processos erosivos são vários, dentre eles destacam-se, a destruição de nascentes, a remoção da camada fértil do solo, o desprendimento e escorregamento de terra e taludes, o aumento do potencial de desertificação, as alterações nas condições de escoamento da água na superfície e na calha dos rios, os desbarrancamentos em rios que modificam a calha e provocam depósitos no leito, produção de sulcos em áreas indesejáveis, e o comprometimento de estruturas (CARVALHO, 1994).

Os processos erosivos são variados e dependem principalmente da natureza do solo, da topografia e dos processos hidrológicos. Nas paisagens de clima úmido, nas regiões onde o solo nunca atinge condição saturada, a erosão difusa predomina, enquanto que nas regiões onde o solo se satura tem-se o predomínio da erosão por lixiviação e ravinamento por escoamento superficial.

Os diferentes tipos de erosão podem ser determinados por meio dos limitantes (thresholds) de erosão, ou seja, o processo erosivo predominante em uma determinada região pode ser identificado, assim como os limites espaciais (fronteira) entre os diferentes processos Este limite espacial entre os diferentes processos erosivos é denominado de limitantes de erosão (erosion threshold) (MONTGOMERY e DIETRICH, 1994). Santos e Kobiyama (2004) traduziram esse termo para o português como "umbral de erosão."

O objetivo do presente estudo foi identificar espacialmente os diferentes processos erosivos que potencialmente ocorrem na BRC. A identificação e o mapeamento dos diferentes tipos erosivos predominantes na bacia do Rio Caeté fornecerão subsídios à tomada de decisão e na adoção de medidas preventivas e mitigadoras preventivas que venham reduzir os impactos negativos ocasionados pelos diferentes tipos erosivos.

$\mathrm{O}$ uso da modelagem possibilita a utilização da experiência já adquirida para a previsão e a compreen- são do sistema ambiental. Apesar de todos os modelos necessitarem de alguma forma de ajuste nos parâmetros, mesmo medidos no campo, a modelagem torna-se uma ferramenta fundamental e de extrema importância. Ela permite a predição de impactos diante de possíveis ações no ambiente. Para tal, o presente trabalho utilizou o modelo proposto e descrito por Dietrich et al. (1992, 1993) e Montgomery e Dietrich (1994), para a simulação dos processos erosivos, que combina condicionantes geomorfológicos, hidrológicos, pedológicos e pluviométricos.

\section{Teoria}

O modelo proposto por Dietrich et al. (1992) determina para cada região (pixel) da bacia hidrográfica o tipo de processo erosivo predominante ou mais suscetível de ocorrência neste, a partir da topografia (declividade e área de contribuição da encosta de montante), da natureza dos solos e de condicionantes hidrológicas. Com base em Dietrich et al. (1992, 1993) e Montgomery e Dietrich (1994), o presente trabalho descreve sucintamente as definições utilizadas por este modelo que permitem identificar e mapear os limites de erosão.

O índice geomorfológico definido pela relação entre a área de contribuição e a unidade de contorno $\left(\mathrm{m}^{2} / \mathrm{m}\right)$ (Figura 1) representa um marco no desenvolvimento da hidrologia (BEVEN e KIRKBY, 1979). Este passa a representar o escoamento por saturação do solo.

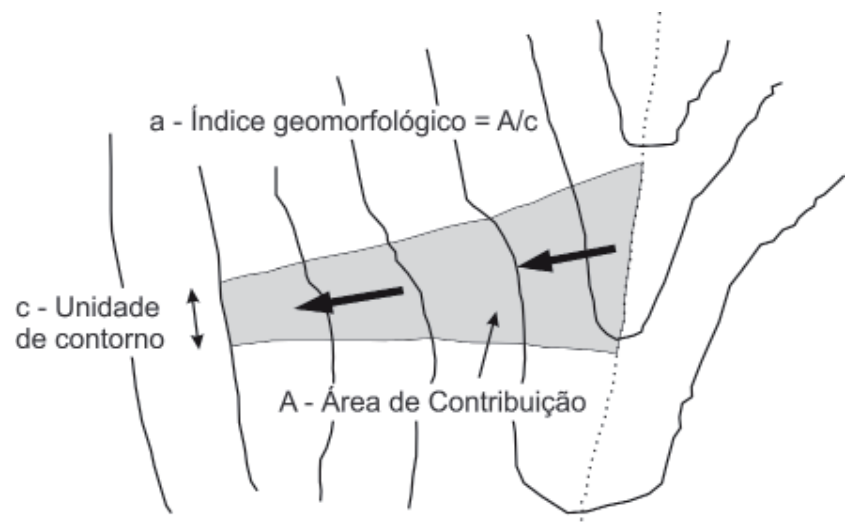

Figura 1 - Definição do índice geomorfológico (a)

O solo é saturado quando o valor do índice geomorfológico for maior ou igual ao valor do lado direito da equação (1), apresentada por Dietrich et al. (1992) e Montgomery e Dietrich (1989, 1994): 


\section{Identificação e Mapeamento dos Processos Erosivos na Bacia Hidrográfica do Rio Caeté}

$$
a \geq \frac{T}{R} \cdot M
$$

onde $a$ é a área de contribuição por unidade de contorno (m); $T$ é a transmissividade do solo $\left(\mathrm{m}^{2} / \mathrm{s}\right) ; R$ é o escoamento lateral subsuperficial do solo saturado, equivalente à precipitação não interceptada $(\mathrm{m} / \mathrm{s})$; e $M$ é o gradiente hidráulico, sendo considerado igual à declividade do terreno $(\mathrm{m} / \mathrm{m})$.

Na obtenção da equação (1), utiliza-se do procedimento proposto por Beven e Kirkby (1979), e O’loughlin (1986) para estimar a distribuição da umidade superficial do solo em bacias hidrográficas. Esta equação indica que, quanto maior a precipitação $(R)$, menor o valor de $a$ necessário para gerar área saturada. Também mostra uma relação log-linear positiva entre $a$ e $M$.

De acordo com Santos e Kobiyama (2004) à medida que se relaciona os valores do índice geomorfológico, $a$, e os de $M$, para cada pixel no Modelo Numérico de Terreno (MNT), pode-se traçar uma linha a partir dos parâmetros hidrológicos $T / R$, sobre a qual os pontos apresentam condição saturada. Nas regiões abaixo deste limite, ou seja, que não se encontram saturadas à superfície, apresentam potencial para desenvolver somente erosão do tipo laminar ou difusa.

Nas áreas saturadas a precipitação incidente, juntamente com o escoamento de retorno irá provocar o escoamento superficial por saturação que potencialmente pode provocar erosão superficial. Nas regiões saturadas podem ocorrer erosões subsuperficiais do tipo Dunne (seepage), quando as condições de coesão do solo permitem a liquefação. A inicialização de canais de erosão (ravinas) provocada por escoamento superficial ocorre quando a resistência mecânica do solo, representada pela tensão de cisalhamento crítica ( $\tau_{c}$ ) é excedida.

De modo geral pode-se considerar que em bacias de clima úmido, relevo suave e com cobertura vegetal, ocorre o predomínio do escoamento superficial dunniano, ou seja, por saturação do solo, em detrimento do escoamento superficial gerado pela água excedente do processo de infiltração, do escoamento hortoniano e que, mesmo que seja rápido, o escoamento superficial em locais com cobertura vegetal pode ser considerado laminar, conforme Montgomery e Dietrich (1994). Dessa forma pode-se assim estimar a área crítica por unidade de contorno necessária para a ocorrência de erosão por escoamento superficial por saturação:

$$
a_{c s} \geq \frac{2 \cdot \tau_{c}^{3}}{k \cdot v \cdot \rho_{a}^{3} \cdot g^{2} \cdot R \cdot M^{2}}+\frac{T \cdot M}{R}
$$

onde $a_{c s}$ é a área crítica por unidade de contorno necessária para a ocorrência de erosão por escoamento superficial por saturação (m); $\tau_{c}$ é a tensão de cisalhamento crítica $\left(\mathrm{N} / \mathrm{m}^{2}\right)$; $k$ é a constante ligada à geometria da superfície (admensional); $v$ é a viscosidade cinemática $\left(\mathrm{m}^{2} / \mathrm{s}\right) ; \rho_{a}$ é a densidade da água (igual a $\left.1000 \mathrm{~kg} / \mathrm{m}^{3}\right)$; e $g$ é a aceleração gravitacional (igual a $9,8 \mathrm{~m} / \mathrm{s}^{2}$ ). A constante $k$ está relacionada com o número de Reynolds e seu significado físico é discutido por Morre e Foster (1990) e Gerits et al. (1990).

Um dos modelos mais simples e mais utilizados para determinar a instabilidade de vertentes é o modelo da vertente infinita (MONTGOMERY e DIETRICH, 1994). Unindo-se hidrologia de vertente com um modelo de instabilidade de vertente, chega-se na seguinte equação para obter a área crítica para deslizamento:

$a_{c d} \geq \frac{z \cdot K \cdot \operatorname{sen} \beta \cdot \cos \beta}{R} \cdot\left[\frac{C}{\rho_{a} \cdot g \cdot z \cdot \cos ^{2} \beta \cdot \tan \phi}+\frac{\rho_{s}}{\rho_{a}} \cdot\left(1-\frac{\tan \beta}{\tan \phi}\right)\right]$

onde $a_{c d}$ é a área crítica por unidade de contorno necessária para a ocorrência de erosão por deslizamento (m); $z$ é a espessura do solo (m); $K$ é a condutividade hidráulica saturada $(\mathrm{m} / \mathrm{s}) ; \beta$ é a declividade da superfície do solo $\left({ }^{\circ}\right)$; $C$ é a coesão efetiva do solo $\left(\mathrm{N} / \mathrm{m}^{2}\right)$; $\phi$ é o ângulo interno de fricção do solo ( $\left.{ }^{\circ}\right)$; e $\rho_{s}$ é a densidade do solo saturado $\left(\mathrm{kg} / \mathrm{m}^{3}\right)$.

A equação (3) é válida somente quando,

$$
\tan \beta \geq\left(\frac{\rho_{s}-\rho_{a}}{\rho_{s}}\right) \cdot \tan \phi \geq \frac{\tan \phi}{2}
$$

Segundo Dietrich et al. (1992), dados de campo indicam que $\left(\rho_{s}-\rho_{a}\right) / \rho_{s}$ é aproximadamente 0,5 . Então, supondo que $C=0$ e considerando-se que $\tan \beta=M$, a equação (3) pode ser escrita como:

$$
a_{c d} \geq 2 \cdot\left(1-\frac{M}{\tan \phi}\right) \cdot \frac{T \cdot M}{R}
$$

Por meio de dados detalhados do MNT e das equações (1), (2) e (5) é possível delimitar na paisagem regiões com predominância dos diferentes processos 
de produção e transporte de sedimentos e dos diferentes mecanismos de inicialização de canais. Em outras palavras, é possível fazer a delimitação espacial dos diferentes processos erosivos que ocorrem em bacias hidrográficas (Figura 2).

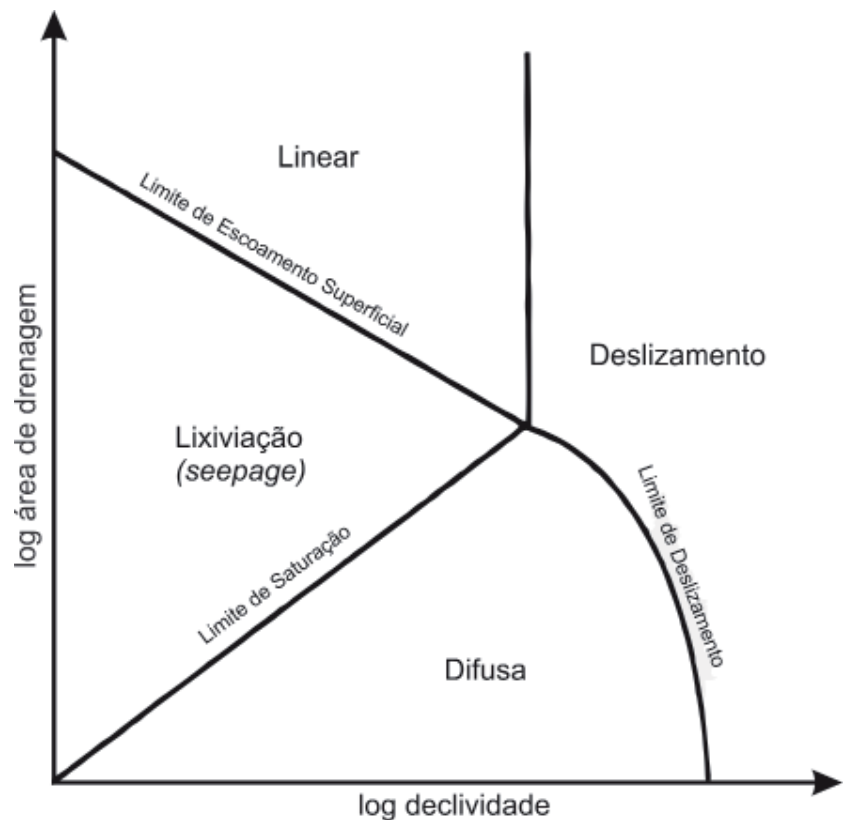

Figura 2 - Definição dos limitantes de erosão (Montgomery e Dietrich, 1994)

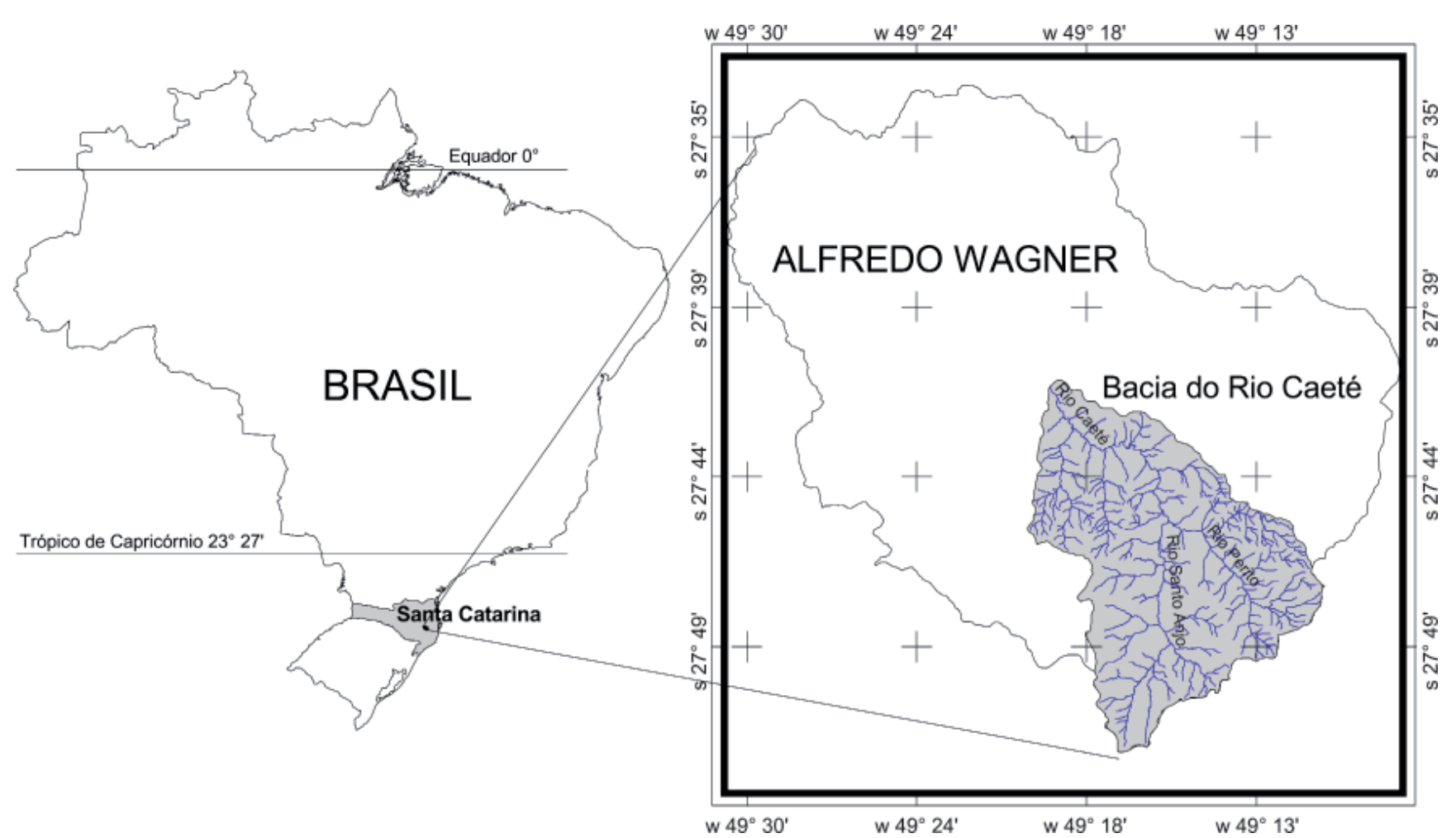

Figura 3 - Localização da BRC

\section{MATERIAIS E MÉTODOS}

\section{Área de estudo}

A BRC, com aproximadamente $163 \mathrm{~km}^{2}$ de área, localiza-se no município de Alfredo Wagner, região serrana do Estado de Santa Catarina, entre as latitudes $27^{\circ} 52^{\prime} 43^{\prime \prime}$ S e $27^{\circ} 41^{\prime} 49^{\prime \prime}$ S e longitudes $49^{\circ} 20^{\prime} 45^{\prime}$ ' W e $49^{\circ} 11^{\prime} 17^{\prime \prime}$ W (Figura 3).

O Rio Caeté é formado pelos rios Perito e Santo Anjo com nascentes em altitudes de 1.140 e 1.600 metros, respectivamente. As densidades de rios e de drenagem na BHC revelaram que a bacia apresenta em média 1,538 rios $/ \mathrm{km}^{2}$ e $1,949 \mathrm{~km} / \mathrm{km}^{2}$, respectivamente, o que caracteriza uma área bem drenada. Estas altas densidades são consequências da estrutura geológica e do relevo da região, caracterizado por um relevo acidentado, com elevadas declividades, que caracteriza os cursos fluviais com um grande número de corredeiras, saltos e cachoeiras, bem como, pelo elevado número de nascentes (VESTENA et al., 2011).

O relevo é dissecado com encostas íngremes, onde atividades de uso inadequadas do solo na bacia tornam mais suscetíveis às ocorrências dos processos erosivas, destacam Checchia et al. (2006). A grande diferença altimétrica (1.293 metros) na BHC reflete em 


\section{Identificação e Mapeamento dos Processos Erosivos na Bacia Hidrográfica do Rio Caeté}

cursos fluviais encachoeirados, com grandes gradientes, favorecendo os processos de transporte de sedimentos fluviais (VESTENA et al., 2011).

O clima na BRC está sob o domínio da zona extratopical, o que resulta em temperaturas com caráter mesotérmico - temperaturas anuais médias entre $16^{\circ} \mathrm{C} \mathrm{e}$ $20^{\circ} \mathrm{C}$, inverno frio e verão amenizado pelas altitudes. As chuvas são abundantes e distribuídas ao longo do ano, portanto, não se distingue um período seco (Monteiro, 1963). A temperatura média anual fica em torno de $19^{\circ} \mathrm{C}$, apresentando oscilações que variam de $-2^{\circ}$ (inverno) a $30^{\circ} \mathrm{C}$ (verão), com a ocorrência de geadas nos meses de inverno. A precipitação média anual fica em torno de $1700 \mathrm{~mm}$, com maiores incidências na primavera e no verão. A umidade relativa média do ar é de $85 \%$ (SANTA CATARINA, 1986).

A geologia na BRC é constituída quase que totalmente por camadas horizontais de arenito, siltitos, argilitos e folhelhos pertencentes à Bacia do Paraná (SHIMIZU et al., 1995).

Nas regiões hipsometricamente mais baixas aparecem rochas mais antigas, do período Permiano da era Paleozóica, do Super-Grupo Tubarão, através do Grupo Itararé, pela formação Rio do Sul, com seus folhelhos, argilitos, siltitos e arenitos. A montante destas e na porção oeste da bacia ocorre o aparecimento da formação Rio Bonito e Palermo, ambos do Grupo Guatá, pertencentes ao Super-Grupo Tubarão (CASTRO et al., 1994).

À medida que se segue a montante e com o aumento das altitudes, principalmente na porção leste que compreende a sub-bacia do Rio Santo Anjo, encontram-se mudanças nas formações geológicas com o aparecimento do Grupo Passa Dois (Período Permiano da Era Paleozóica), que compreende cronologicamente as formações Irati, Serra Alta, Teresina e Rio do Rastro. Nos pontos mais elevados, encontra-se o surgimento do Grupo São Bento, através das formações Botucatu e Serra Geral, pertencente a feições geológicas mais recentes dos períodos Triássico, Jurássico e Cretáceo da era Mezosóica (CASTRO et al., 1994).

Os solos que predominam na BRC são os Cambissolo e Neossolos (Figura 4). Estes apresentam fertilidade natural muito baixa, refletida pelo caráter álico (alta saturação de alumínio). Estas características identificam os solos de encostas (de estrutura frágil e facilmente erodíveis) e os das chapadas (extremamente ácidos). Os Cambissolos se apresentam com sequência incompleta de horizontes, com pouca diferenciação entre si e bem drenados. O horizonte A é no geral do tipo proeminente. É cascalhento e sua textura varia de média a argilosa, possuindo elevados teores de silte, alta capacidade de troca catiônica e horizonte B pouco espesso. Os Cambissolos apresentam grau de suscetibilidade à erosão variável, dependendo da declividade, do teor de silte, do gradiente textural e da sua profundidade (SACHET, 1994).

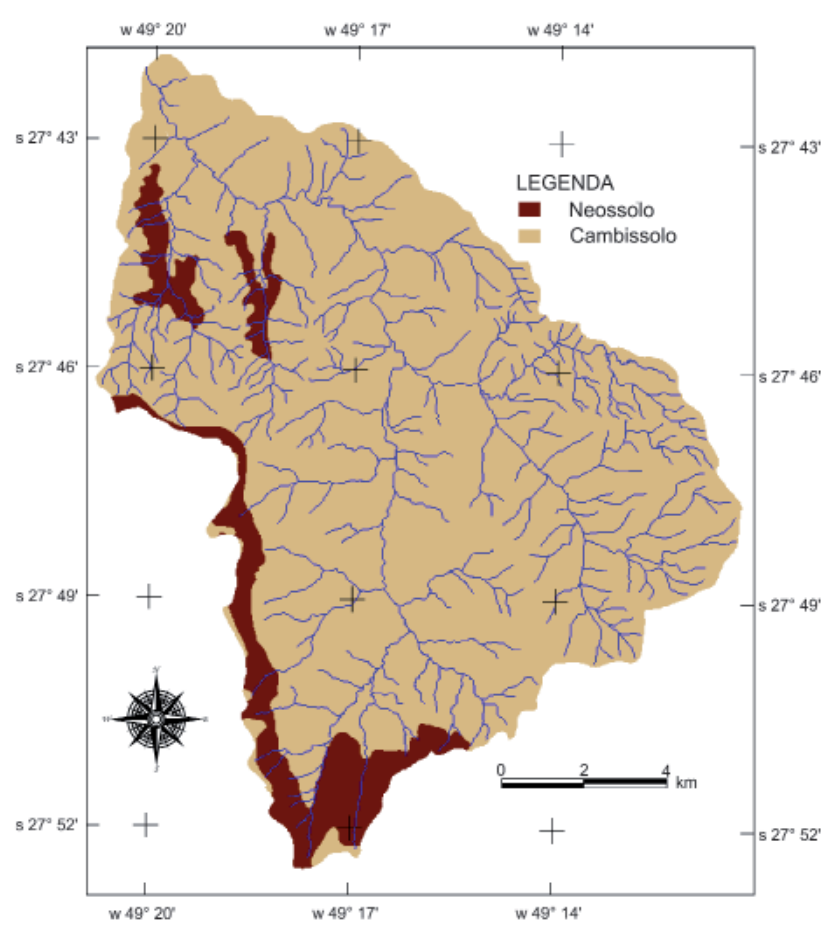

Figura 4 - Tipo de solos (Checchia et al., 2006)

O uso do solo e cobertura da terra é caracterizado por matas, reflorestamento, campo, solos expostos e cultivos. Segundo o mapeamento temático das classes de uso do solo e cobertura da terra realizadas por Viecili (2005), na BRC as áreas com mata nativa predominam em 52,2\% da mesma, seguido por $41,8 \%$ de campo, $2,2 \%$ de solos expostos, 2,1\% de reflorestamento e $1,7 \%$ de cultivos (Figura 5). A principal atividade agrícola é o cultivo da cebola, associada geralmente com lavouras de feijão e milho, no geral, em pequenas propriedades.

\section{Materiais, variáveis e parâmetros utilizados}

Santos e Kobiyama (2004) desenvolveram um programa computacional que exerce o modelo proposto 


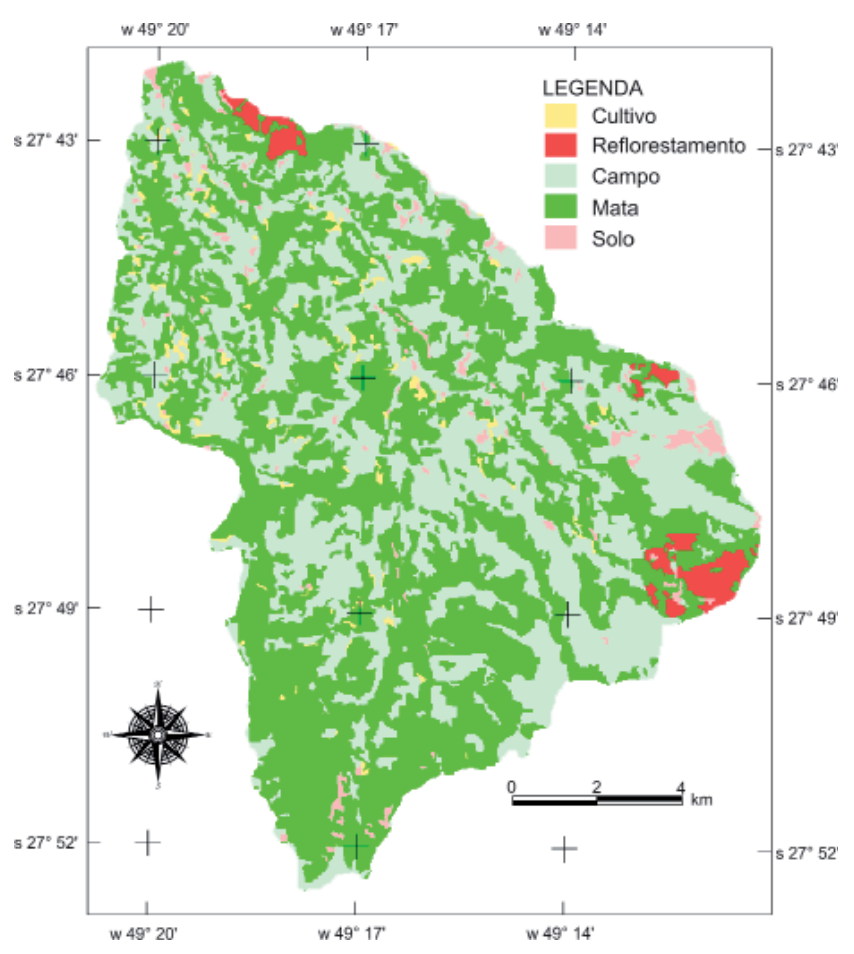

Figura 5 - Uso do solo e cobertura da terra (Viecili, 2005)

por Montgomery e Dietrich (1994), e chamaram esse programa de Umbral. O programa Umbral classifica os tipos de processos erosivos por meio da declividade, do índice geomorfológico, distribuídos espacialmente por meio de uma grade numérica da área de estudo.

Para tal utilizou-se de uma base cartográfica obtida a partir das cartas topográficas, com equidistância entre as curvas de nível de 20 metros, do Instituto Brasileiro de Geografia e Estatística - IBGE (Tabela 1).

A declividade e o índice geomorfológico foram obtidos por meio do modelo de elevação digital (DEM), gerado a partir dos dados topográficos (curvas de níveis e pontos cotados), com resolução de 30x30 metros.

As demais variáveis necessárias para simulação nesse programa foram a precipitação de projeto e os parâmetros geotécnicos e hidrológicos de solo (ângulo interno de fricção; transmissividade do solo; constante ligada à geometria da superfície; e tensão de cisalhamento crítica) (Tabela 2).

O valor médio do ângulo interno de fricção $(\phi)$ adotado levou em consideração os tipos de solo presentes na BRC. Na bacia o solo que predomina é o Cambissolo, ou seja, está presente em mais de $90 \%$ da área desta (Figura 4). Diante disso, o valor médio do ângulo interno de friç̧ão utilizado foi obtido da média dos valores medidos por Santos e Kobiyama (2004) para Cambissolos, em diferentes condições de uso (agricultura e campo), por meio de ensaios de cisalhamento. Assim, o valor da coesão média obtido por Santos e Kobiyama (2004) para Cambissolos, isto é, 10,65 kPa, foi utilizado no presente trabalho.

O valor adotado da tensão de cisalhamento crítica foi calculado a partir dos dados apresentados por Komura (1982) que relaciona coesão $C$ e tensão de cisalhamento crítica $\tau_{c}$ para solos coesivos.

A precipitação de projeto $(R)$ foi estimada a partir dos dados diários de precipitações da estação pluvio-

Tabela 1 - Descrição das cartas topográficas utilizadas

\begin{tabular}{ccccc}
\hline MI & Índice de nomenclatura & Nome da folha & Editor & Escala \\
\hline $2908-1$ & SG.22-Z-D-IV-1 & Alfredo Wagner & IBGE & $1: 50000$ \\
\hline $2908-2$ & SG.22-Z-C-IV-2 & Rancho Queimado & IBGE & $1: 50000$ \\
\hline $2908-3$ & SG.22-Z-C-IV-3 & Bom Retiro & IBGE & $1: 50000$ \\
\hline $2908-4$ & SG.22-Z-C-IV-4 & Anitápolis & IBGE & $1: 50000$ \\
\hline
\end{tabular}

Tabela 2 - Parâmetros utilizados na simulação dos limitantes de erosão

\begin{tabular}{clcc}
\hline Parâmetro & \multicolumn{1}{c}{ Descrição } & Valor adotado & Unidade \\
\hline$\tau_{c}$ & Tensão de cisalhamento crítica & 23,1 & $\mathrm{~N} / \mathrm{m}^{2}$ \\
\hline$\phi$ & Ângulo interno de fricção & 33,6 & graus \\
\hline$K$ & Constante ligada à geometria da superfície & 10000 & adimensional \\
\hline$R$ & Precipitação de projeto & 0,08 & $\mathrm{~m} /$ dia \\
\hline $\mathrm{T}$ & Transmissividade do solo & 22,52 & $\mathrm{~m} 2 / \mathrm{dia}$ \\
\hline
\end{tabular}




\section{Identificação e Mapeamento dos Processos Erosivos na Bacia Hidrográfica do Rio Caeté}

métrica Lomba Alta, código 02749037 - ANA(Agência Nacional de Águas), localizada no município de Alfredo

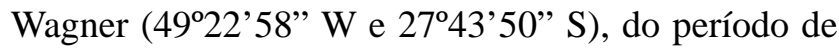
01/1941 a 12/2000, adotando-se o valor médio das máximas diárias anuais.

O valor da transmissividade do solo (T) adotado foi obtido da calibração do TOPMODEL (TOPography based hydrological MODEL) para a BRC, realizada por Vestena (2008) e para a constante relacionada com a geometria da superfície $(k)$ o mesmo valor adotado por Dietrich et al. (1992).

\section{Aplicação do modelo de Dietrich et al. (1992)}

A simulação deu-se por meio de rotina desenvolvida por Santos e Kobiyama (2004) com o auxílio do software ArcView 3.2. A Figura 6 mostra o fluxograma das atividades desenvolvidas para a utilização do programa Umbral.

Por meio da sobreposição dos mapas de uso do solo e cobertura da terra e de processos erosivos, segundo Santos e Kobiyama (2004), pode-se estabelecer um diagnóstico ambiental da bacia hidrográfica. Para tal, as classes de uso do solo e cobertura da terra foram agrupadas em duas categorias: natural (mata) e antrópica (cultivo, solo, campo e reflorestamento) e sobrepostas às classes dos processos erosivos com o auxílio do software Spring 4.3.2, desenvolvido pelo Instituto Nacional de Pesquisas Espaciais (INPE).

\section{RESULTADOS E DISCUSSÕES}

As declividades na BRC são acentuadas, destacando-se na porção sul e sudoeste da mesma, onde se encontram os maiores índices de declividade, principalmente nas nascentes do Rio Santo Anjo (Figura 7a). Assim como que as declividades acima de $45 \%$ estão presentes em aproximadamente $20 \%$ das áreas da bacia, característica essa que potencializa, ou seja, torna mais suscetível a ocorrência de processos erosivos.

No mapa do índice geomorfológico (Figura 7b) verifica-se nitidamente a rede de drenagem, representada pelos maiores valores, e os divisores de água da bacia com os menores valores. Este fator demonstra a importância da topografia na concentração do escoamento superficial.

Na Figura 8 têm-se os diversos processos erosivos reconstruídos por meio de aplicação do modelo para a



Figura 6 - Fluxograma dos procedimentos adotados (Santos e Kobiyama, 2004)

BRC. Percebem-se grandes áreas suscetíveis à ocorrência de deslizamentos (Tabela 3). A erosão por lixiviação atinge 50,4\% da área total da BRC, e está presente em toda a extensão da bacia, mais especificadamente nas áreas saturadas de relevo plano. A erosão difusa esteve presente em 15,6\% da BRC e apesar de estar distribuída, concentra-se em maior número na margem esquerda do curso inferior do Rio Caeté. A erosão linear está dispersa por toda a extensão da bacia. Este tipo de erosão atinge apenas $4,9 \%$ da área total.

A erosão por deslizamento atinge 29,1\% da área total e está mais presente principalmente no alto curso do Rio Santo Anjo, localizada junto às maiores declividades. A rede de drenagem está encaixada em vales na forma de $\mathrm{V}$, próximo à incisão do curso fluvial tem-se um relevo na forma de escarpa, neste verifica-se a potencialidade natural da ocorrência de deslizamentos.

A Figura 9 e a Tabela 3 mostram o uso do solo e cobertura da terra nas áreas de recorrência dos diferentes processos erosivos. Nestes verifica-se que nas áreas que apresentam erosão por lixiviação são as que recebem maiores influências das atividades antrópicas. Isso pode ser explicado pelo motivo de serem áreas planas, o que facilita a prática agrícola. 
Vestena L. R. \& Kobiyama M.
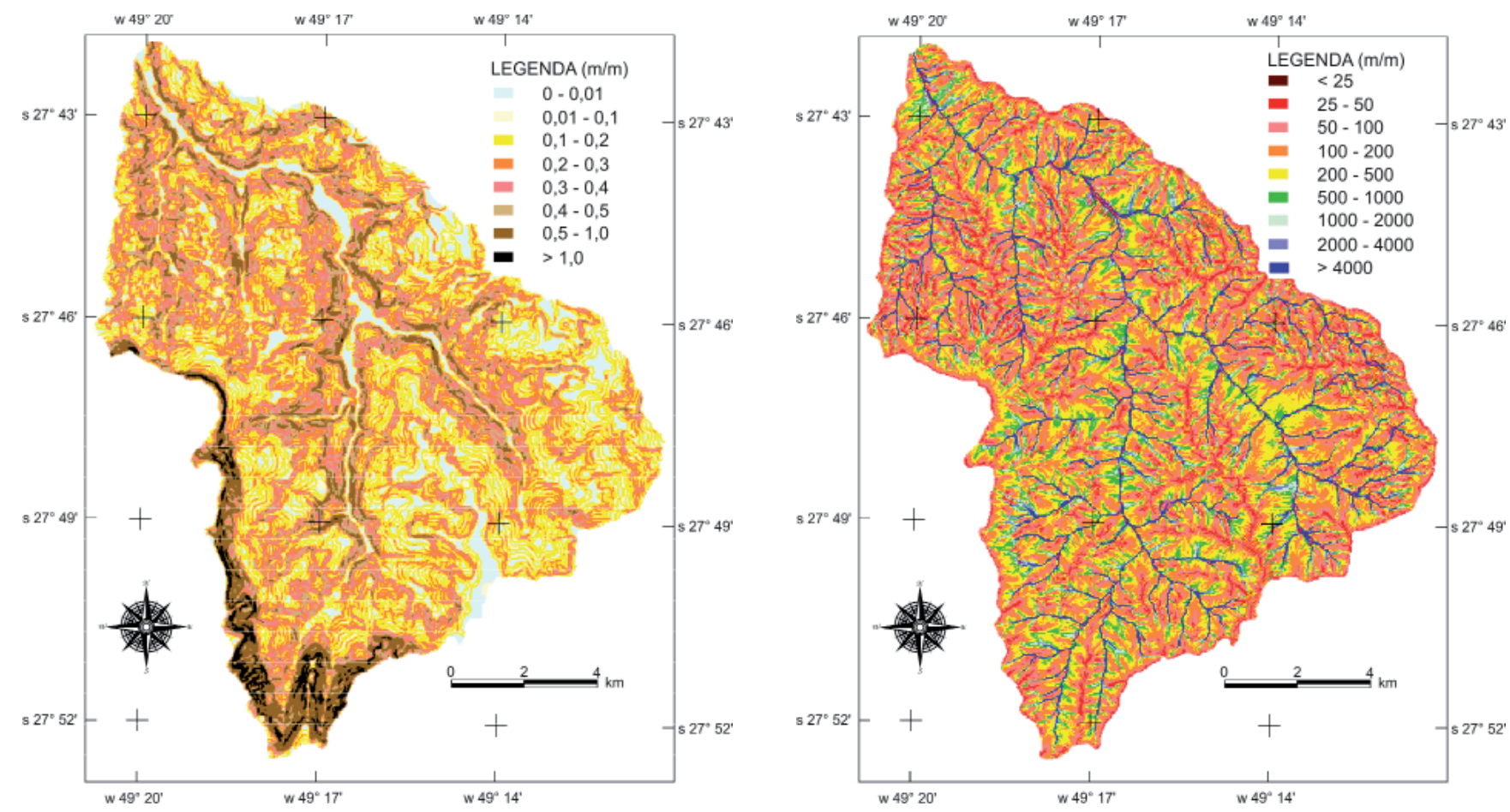

Figura 7 - Características geomorfológicas: (a) Declividade ( $\tan \beta$ ) e (b) Índice geomorfológico



Figura 8 - Processos erosivos na BRC

Os processos erosivos são influenciados pela forma do relevo, pois os sedimentos erodidos das vertentes pela ação da água são transportados em sua maioria para níveis patamares, ou seja, superfícies planas ou levemente inclinadas interrompem a continuidade do declive da vertente (controle geológico), principalmente para as

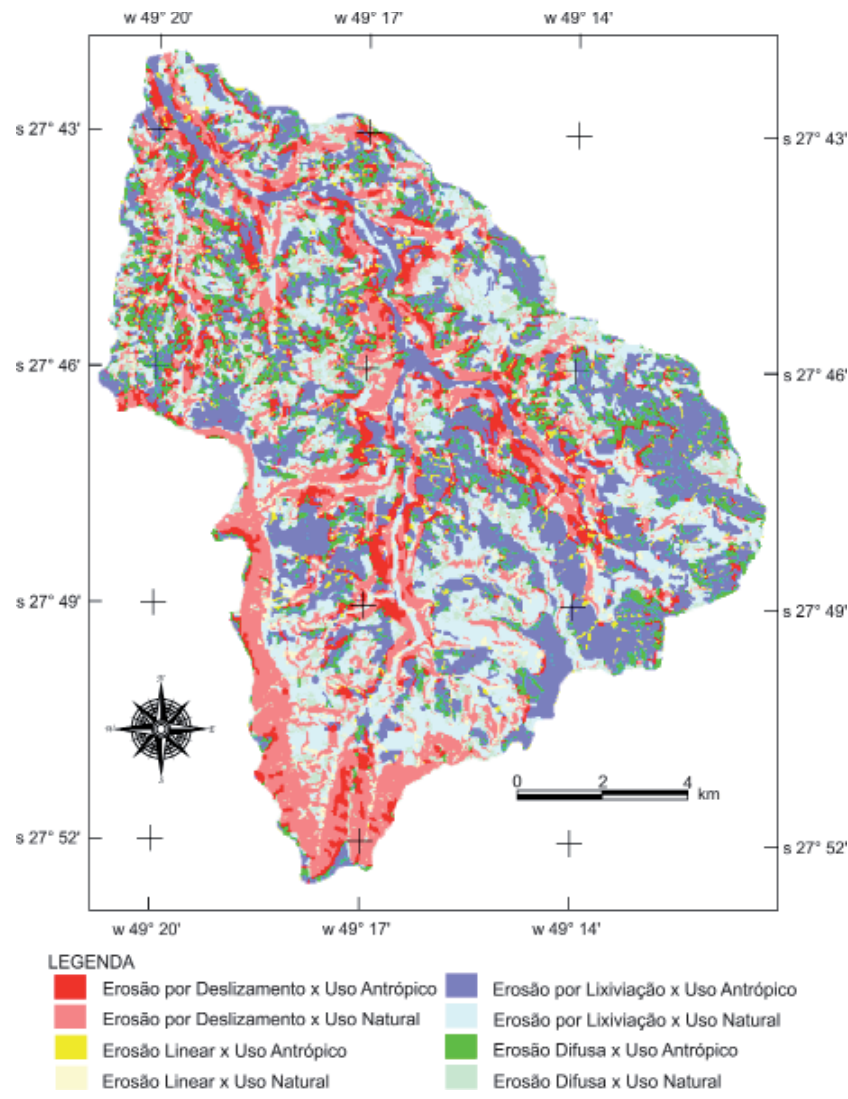

Figura 9 - Diagnóstico ambiental (uso do solo e cobertura da terra x processo erosivo)

planícies de inundações e os terraços fluviais. A Figura 10 mostra uma visão parcial das principais unidades do 
Identificação e Mapeamento dos Processos Erosivos na Bacia Hidrográfica do Rio Caeté

Tabela 3 - Áreas dos processos erosivos predominantes na BRC

\begin{tabular}{|c|c|c|c|c|c|}
\hline $\begin{array}{c}\text { Tipo de processo erosivo } \\
\text { predominante }\end{array}$ & $\begin{array}{l}\text { Área } \\
\left(\mathbf{k m}^{2}\right)\end{array}$ & $\begin{array}{l}\text { \% Total } \\
\text { da bacia }\end{array}$ & $\begin{array}{c}\text { Uso do solo e } \\
\text { cobertura da } \\
\text { terra } \\
\end{array}$ & $\begin{array}{l}\text { Área } \\
\left(\mathbf{k m}^{2}\right)\end{array}$ & $\begin{array}{l}\text { \% Total } \\
\text { da bacia }\end{array}$ \\
\hline \multirow{2}{*}{ Erosão difusa } & \multirow{2}{*}{25,68} & \multirow{2}{*}{15,6} & Natural & 12,99 & 7,9 \\
\hline & & & Antrópico & 12,70 & 7,7 \\
\hline \multirow{2}{*}{ Erosão por lixiviação } & \multirow{2}{*}{82,86} & \multirow{2}{*}{50,4} & Natural & 35,41 & 21,5 \\
\hline & & & Antrópico & 47,41 & 28,8 \\
\hline \multirow{2}{*}{ Erosão linear } & \multirow{2}{*}{8,08} & \multirow{2}{*}{4,9} & Natural & 4,76 & 2,9 \\
\hline & & & Antrópico & 3,34 & 2,1 \\
\hline \multirow{2}{*}{ Erosão por deslizamento } & \multirow{2}{*}{47,81} & \multirow{2}{*}{29,1} & Natural & 32,68 & 19,9 \\
\hline & & & Antrópico & 15,11 & 9,2 \\
\hline Área total & 164,40 & 100 & & 164,40 & 100 \\
\hline
\end{tabular}

relevo presente na BHC e o processo erosivo dominante.

A partir dos resultados obtidos pode-se inferir que as características da BRC apresentam fragilidade natural que beneficiam a ocorrência de processos erosivos. Diante desta fragilidade, um manejo adequado do uso do solo e cobertura da terra torna-se de fundamental importância para minimizar e prevenir a atuação dos processos erosivos, pois atividades realizadas sem um planejamento prévio, como a retirada da vegetação, entre outras podem ocasionar a intensificação dos processos erosivos.
A identificação e o mapeamento dos tipos de processos erosivos servem de indicação a ações de manejo do uso do solo. Contudo, estudos mais detalhados são necessários como apontaram Kobiyama et al. (2012), por exemplo, o tipo de uso do solo e cobertura da terra floresta, dependendo das características (componentes e condições) pode ocasionar efeitos potencializadores ou mitigadores de deslizamentos. Uma vez que as raízes em área florestada aumentam a coesão do solo, mas a vegetação exerce uma carga (peso) sobre a encosta (BORGA et al. (2002).

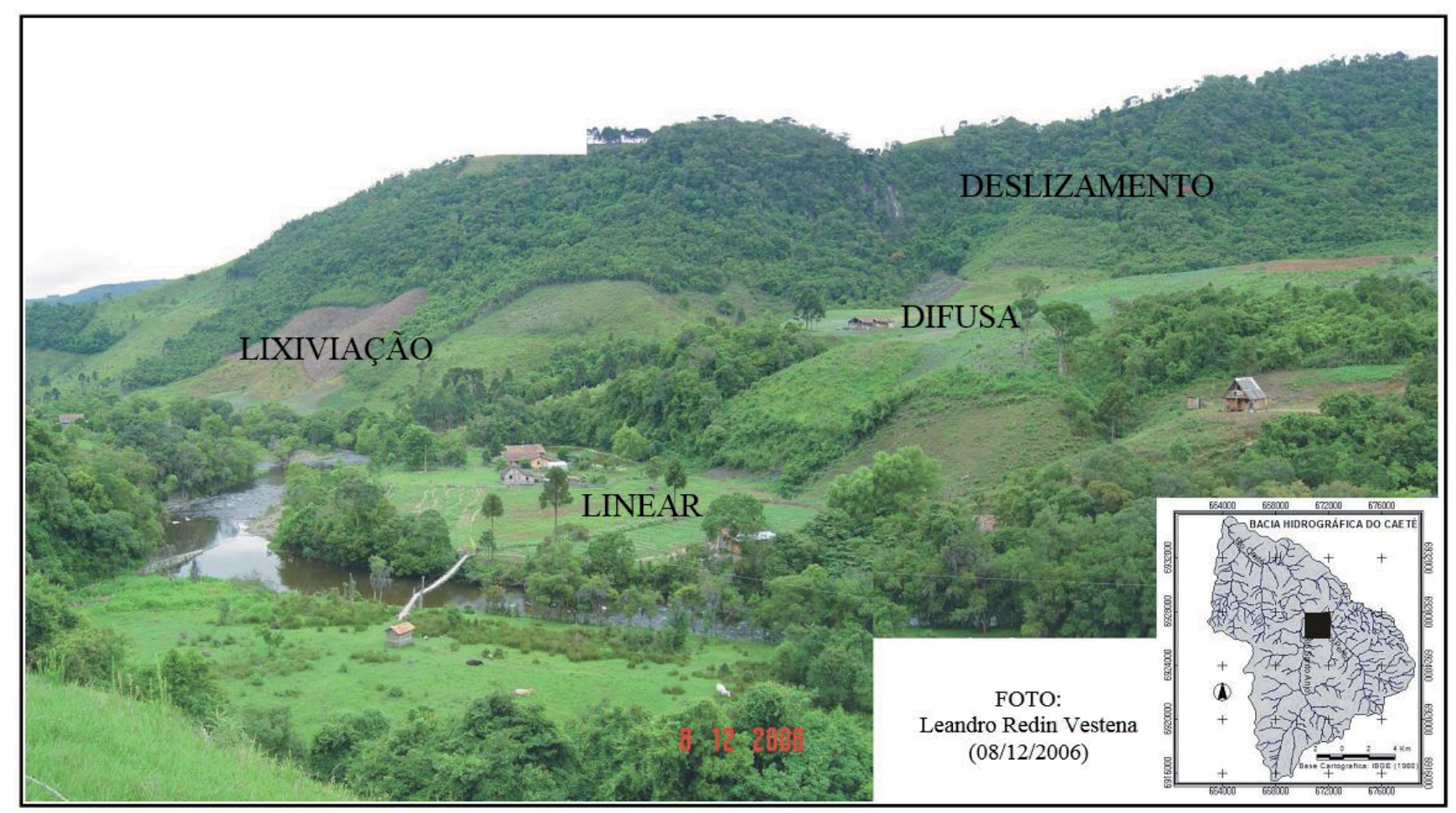

Figura 10 - Processos erosivos dominantes: visão parcial do vale do Rio Perito próximo a sua foz com o Rio Santo Anjo, porção central da BRC 


\section{CONSIDERAÇÕES FINAIS}

A identificação e o mapeamento dos tipos de processos erosivos predominante subsidiam a tomada de decisão, no sentido de prevenir e/ou amenizar os impactos ocasionados pelos mesmos, por meio de ações antrópicas planejadas e orientadas sobre o meio físico. Assim sendo, a fim de auxiliar a gestão territorial no município de Alfredo Wagner, Santa Catarina, que vem sofrendo com problemas hídricos e sedimentares, o presente estudo aplicou o modelo proposto de Dietrich et al. (1992) à BRC que localiza-se dentro deste município.

O resultado da simulação apresentou que as áreas de erosão por lixiviação, erosão por deslizamento, erosão difusa e erosão linear atingem 50,4\%, 29,1\%, 15,6\% e 4,9\% da área total da BRC, respectivamente. Verificou-se que as áreas de erosão por lixiviação recebem maiores influências das atividades antrópicas.

A observação da paisagem em campo, junto aos resultados da simulação, demonstra que o modelo de Dietrich et al. (1992) é uma ferramenta pertinente na identificação e no zoneamento dos diferentes tipos de erosão presentes na BRC. Como ele se constitui em um modelo de fácil aplicação e uma ferramenta de grande utilidade para o diagnóstico e a análise ambiental, poderá ser aplicado para outras regiões que sofrem problemas de erosão hídrica.

\section{AGRADECIMENTOS}

Os autores agradecem ao Conselho Nacional de Desenvolvimento Científico e Tecnológico (CNPq) pelo financiamento da pesquisa e ao professor Irani dos Santos do Departamento de Geografia da Universidade Federal do Paraná pela disponibilização do programa Umbral.

\section{REFERÊNCIAS}

BORGA, M.; FONTANA, G.D.; GREGORETTI, C.; MARCHI, L. Assessment of shallow landsliding by using a physically based model of hillslope stability. Hydrologycal Processes, v.16, p. 2833-2851, 2002.

BEVEN, K. J.; KIRKBY, M. J. A physically based variable contributing area model of basin hydrology. Hydrological Sciences Bulletin, v. 24, n. 1, p. 43-69, 1979.

CARVALHO, N. O. Hidrossedimentologia prática. Rio de
Janeiro: CPRM, 1994. 372 p.

CHECCHIA, T.; KOBIYAMA, M.; SILVA, R.V.; ALVES, A. Análise preliminar da evolução dos deslizamentos no vale do rio Caeté, Alfredo Wagner, SC. In: SIMPÓSIO NACIONAL DE GEOMORFOLOGIA, 5., 2004, Santa Maria. Anais... Santa Maria: UFSM, 2004. 1 CD-ROM

CHECCHIA, T.; VESTENA, L. R.; KOBIYAMA, M.; SCHRÖDER, P. H. Interação entre climatologia, geologia e geomorfologia na bacia hidrográfica do Caeté, município de Alfredo Wagner, SC. In: XV SEMANA DE GEOGRAFIA, 4., 2006, Guarapuava. Anais... Guarapuava: UNICENTRO, 2006. p. 121-133.

DIETRICH, W. E.; WILSON, C. J.; MONTGOMERY, D. R.; MCKEAN, J.; BAUER, R. Channelization thresholds and land surface morphology. Geology, v. 20, p. 675-679, 1992.

DIETRICH, W. E.; WILSON, C. J.; MONTGOMERY, D. R.; MCKEAN, J. Analysis of erosion thresholds, channel networks and landscape morphology using a digital terrain model. Journal of Geology, v. 101, p. 259-278, 1993.

CASTRO, J.C.; BORTOLUZZI, C.A.; CARUSO Jr., F.; KREBS, A. S. Coluna White: Estratigrafia da Bacia do Paraná no Sul do Estado de Santa Catarina - Brasil. Florianópolis: Secretaria de Estado de Tecnologia, Energia e Meio Ambiente, 1994. 1 v. (Série Textos Básicos de Geologia e Recursos Minerais de Santa Catarina, 4). 68p.

GERITS, J. J. P.; DELIMA, J. L. M. P.; VAN DEN BROEK, T. M. W. Overland flow and erosion. In. ANDERSON, M. G.; BURT, T. P. (Eds.). Process studies in hillslope hydrology. Chichester: J. Wiley, 1990. p. 173-214.

KOBIYAMA, M.; MICHEL, G. P.; GOERL, R. F. Relação entre desastres naturais e floresta. Revista Geonorte, v. 1, n 6, p. 17-48, 2012.

KOMURA, S. Hidráulica de sedimentos I. Tokyo: Morikita Publishing Co., 1982. 339 p. (em japonês).

MONTEIRO, C. A. F. O clima. In: Geografia Regional do Brasil: Grande Região Sul. Volume IV. Tomo I. Cap. III. Biblioteca Geográfica Brasileira, IBGE, CBG, Rio de Janeiro, 1963. p. 117-169.

MONTGOMERY, D. R.; DIETRICH, W. E. Landscape dissection and drainage area-slope thresholds. In: KIRKBY, M. J. (Ed.). Process models and theoretical geomorphology. John Wiley and Sons., 1994. p. 221-246.

MONTGOMERY, D. R.; DIETRICH, W. E. Source areas, drainage density, and channel initiation. Water Resources 


\section{Identificação e Mapeamento dos Processos Erosivos na Bacia Hidrográfica do Rio Caeté}

Research, v. 25, n. 8, p. 1907-1918, August 1989.

MORRE, I. D.; FOSTER, G. R. Hydraulics and overland flow. In. ANDERSON, M. G.; BURT, T. P. (Eds.). Process studies in hillslope hydrology. Chichester: J. Wiley, 1990. p. 215-254.

O’LOUGHLIN, E. M. Prediction of surface saturation zones in natural catchments by topographic analysis. Water Resources Research, v. 22, n. 5, p. 794-804, 1986.

PACK R. T., TARBOTON D. G., GOODWIN C. N. The SINMAP Approach to Terrain Stability Mapping. In: CONGRESS OF THE INTERNATIONAL ASSOCIATION OF ENGINEERING GEOLOGY, 8., 1998, Vancouver, British Columbia, Canada, 21-25 September 1998. Disponível em: <http:// www.crwr.utexas.edu/gis/gishydro99/uwrl/sinmap/iaeg.pdf> Acessado em 10 fev. 2014.

SACHET, Z. P. Levantamento edafoclimatológico da microbacia do Rio Caeté. Documento Técnico n. 20. Florianópolis: FAPEU, 1994.

SANTA CATARINA. Gabinete de Planejamento e Coordenação Geral. Atlas do Estado de Santa Catarina. Rio de Janeiro, 1986. 173 p.

SANTOS, I.; KOBIYAMA, M. D. Delimitação espacial de diferentes processos erosivos na bacia do rio Pequeno, São José dos Pinhais - PR. In: SIMPÓSIO BRASILEIRO DE DESASTRES NATURAIS, 1., 2004, Florianópolis. Anais... Florianópolis: GEDN/UFSC, 2004. p. 174-187. 1 CD-ROM.

SHIMIZU et al. Síntese temática: geologia. In: Projeto Gerenciamento Costeiro: $\mathbf{2}^{\mathbf{0}}$ Fase. Florianópolis: IBGE, 1995. 231 p. Mapas

VESTENA, L. R. Análise da relação entre a dinâmica de áreas saturadas e o transporte de sedimentos em uma bacia hidrográfica por meio do monitoramento e modelagem. 2008. 303 f. Tese (Doutorado em Engenharia Ambiental) Universidade Federal de Santa Catarina, Florianópolis, 2008.

VESTENA, L. R.; CHECCHIA, T.; KOBYIAMA, M. Análise morfométrica e geomorfológica da bacia hidrográfica do Caeté, Alfredo Wagner/SC. Bol. geogr., Maringá, v. 29, n. 2, p. 93106, 2011.

VIECILI, F. L. Mapeamento temático do uso e cobertura do solo na bacia do Caeté, município de Alfredo Wagner, SC. 2005. 197 f. Dissertação (Mestrado em Engenharia Ambiental) - Universidade Federal de Santa Catarina, Florianópolis, 2005. 